\title{
Physically active patients with coronary artery disease: A longitudinal investigation of the processes of exercise behaviour change
}

\author{
Martina Kanning* \\ Department of Sport and Exercise Science, University of Stuttgart, \\ Germany
}

Objectives. Although regular exercise is important for patients with coronary artery disease (CAD), most CAD patients are not sufficiently active. The transtheoretical model offers a framework for the process of exercise behaviour change. But until today, it is not clear which processes of exercise behaviour change (POC) support CAD patients in maintaining exercise after discharge.

Design. A longitudinal study with baseline measure and 6 month follow up has been conducted. German CAD patients were mailed at home after discharge. POC and exercise were self reported.

Methods. A total of 204 CAD patients were selected from five rehabilitation centres. A total of $108 \mathrm{CAD}$ patients, which were in the post action stages, provided data at baseline and follow up. Two different analyses were carried out. Firstly, structural equation modelling with baseline data $(N=147)$ was used to test the hierarchical order of the POC in experiential and behavioural processes. Secondly, cross lagged panel analysis was used to investigate whether POC lead to exercise or vice versa and which POC support CAD patients in maintaining exercise.

Results. Comparative analysis indicates that the two hierarchical factor model fits the data significantly better than the one hierarchical factor model $\left(\chi^{2} \operatorname{diff}_{(I)}=19.04\right.$, $p<.00 \mathrm{I})$, even though experiential and behavioural processes are highly correlated $(r=.98, p<.001)$. Standardized effects of the antecedent cross lags are significant for consciousness raising $(\beta=0.27)$, reinforcement management $(\beta=0.28)$, self liberation $(\beta=0.28)$, and stimulus control $(\beta=0.33)$ indicating that these POC are predictive for CAD patients maintaining exercise.

Conclusion. Although some POC support the exercise behaviour change process and the hierarchical structure is apparent, it may be beneficial to adapt the POC to give a more precise understanding of the change processes.

* Correspondence should be addressed to Dr Martina Kanning, Department of Sport and Exercise Science, University of Stuttgart, Allmandring 28, 70569 Stuttgart, Germany (e-mail: martina.kanning@sport.uni-stuttgart.de). 
Coronary artery disease (CAD) is the main cause of death in industrialized countries. Of the world population, $29.2 \%$ die due to CAD, and the World Health Organization (WHO) estimates that the incidence rate of CAD will increase in the next few years (World Health Organisation [WHO], 2004).

Today, CAD patients receive effective medical care including invasive surgery when necessary (e.g., Leon et al., 2005). Furthermore, CAD patients are encouraged to change risk-related behaviours such as inactivity, smoking, and the consumption of unhealthy foods. According to the results of a review including only randomized controlled trials, changing these risk-related behaviours is at least as effective as medical care (Kolenda, 2005).

According to Thompson et al. (2003, p. 3113), inactivity is a 'major CAD risk factor'. Physical inactivity is responsible for $22 \%$ of CAD incidences (WHO, 2004). In addition, several studies have shown that exercising is even good for the health of people already suffering from CAD (Niebauer et al., 1997; Wannamethee, Shaper, \& Walker, 2000).

Unfortunately, however, most CAD patients are not sufficiently active. In Germany, $1,022 \mathrm{CAD}$ patients were asked about their level of physical activity 1 year after discharge. The majority of the sample exercises regularly with low to moderate intensity and follows the recommendations of the American Association of Cardiovascular and Pulmonary Rehabilitation. Nevertheless, $40 \%$ of the CAD patients do not achieve the recommended extra caloric use of 1,000 kcal per week (Müller-Fahrnow, Karoff, \& Nowossadeck, 2003). During rehabilitation, CAD patients receive extensive information on how to life a healthy life-style. But apparently many CAD patients are not able to transfer the exercise behaviour they have learned during rehabilitation successfully into their everyday lives (Schlicht, Kanning, \& Bös, 2006).

The transtheoretical model of behaviour change (TTM; e.g., Prochaska \& DiClemente, 1986) is a framework for interventions and wants to explain the exercise behaviour change process. It is a multi-stage model integrating different constructs drawn from different theories of behaviour change and systems of psychotherapy into a single coherent model. The TTM includes four core constructs: decisional balance, selfefficacy, stages of change (SOC), and processes of changes (POC) (Prochaska, Reeding, \& Evers, 2002). Decisional balance reflects the individual's weighing of the pros and cons of behaviour changing. Self-efficacy was integrated from Bandura's (1982) selfefficacy theory. The construct describes the situation-specific confidence that people have in respect to coping with problems without relapsing (e.g., I will certainly go running although it is raining). SOC make up the central construct describing the dynamic process of behaviour change. The merit of TTM is that it does not construe behaviour change as a finite event but as a progress. However, the stages were criticized extensively (e.g., West, 2005). For exercise, five stages referring to the readiness for behaviour change have been identified. The SOC are pre-contemplation (not thinking about becoming active), contemplation (thinking about exercising in the next 6 months), preparation (planning to exercise in the next 30 days), action (exercising for less than 6 months), and maintenance (exercising regularly for at least 6 months; Marcus \& Simkin, 1994). Within this temporal dimension of the SOC, POC specify how these changes occur. The TTM postulates five covert activities (experiential processes) and five overt activities (behavioural processes) that individuals engage in order to progress through stages (Table 1). According to the theoretical framework of the TTM, in the early stages a person will mainly evaluate the new behaviour (experiential processes), while evaluating themselves or while raising awareness of their unhealthy behaviour. In the later stages, processes and strategies are relevant which support the new 
Table I. Processes of behaviour change, adapted from Prochaska et al. (2002)

\begin{tabular}{ll}
\hline & Description \\
\hline $\begin{array}{l}\text { Experiential processes of change } \\
\text { Consciousness raising }\end{array}$ & $\begin{array}{c}\text { Finding and learning new facts and ideas that support the healthy } \\
\text { behaviour change } \\
\text { Experiencing the negative emotions that go along with unhealthy } \\
\text { behavioural risks } \\
\text { Reamatic relief }\end{array}$ \\
$\begin{array}{l}\text { Realizing the negative impact of the unhealthy behaviour or the } \\
\text { positive impact of the healthy behaviour on one's proximal } \\
\text { social and physical environment }\end{array}$ \\
$\begin{array}{l}\text { Realizing that the behaviour change is an important part of one's } \\
\text { identity as a person }\end{array}$ \\
Social liberation & $\begin{array}{l}\text { Realizing that the social norms are changing in the direction of } \\
\text { supporting the healthy behaviour change }\end{array}$ \\
$\begin{array}{l}\text { Behavioural processes of change } \\
\text { Counter conditioning }\end{array}$ & $\begin{array}{c}\text { Substituting healthier alternative behaviours and cognitions for the } \\
\text { unhealthy behaviour }\end{array}$ \\
Helping relationships & $\begin{array}{l}\text { Using social support for the healthy behaviour change } \\
\text { Increasing the rewards for the positive behaviour change } \\
\text { Reinforcement management } \\
\text { Self liberation } \\
\text { Stimulus control }\end{array} \quad \begin{array}{l}\text { Making a firm commitment to change } \\
\text { Removing reminders or cues to engage in the unhealthy behaviour } \\
\text { and adding cues and reminders to engage in the healthy } \\
\text { behaviour }\end{array}$ \\
\hline
\end{tabular}

behaviour (behavioural processes). These strategies include strategies for selfreinforcement, for instance (Prochaska et al., 2002).

Surprisingly, the POC have hardly been examined and there are critical comments about whether the higher-order structure of the POC is useful in the domain of physical activity. A meta-analysis (Rosen, 2000) shows that maintaining regular physical activity in contrast to quitting smoking - needs both experiential and behavioural processes in the early stages, and all of the 10 POC increase up to the later stages - 'they are used in tandem rather than sequentially' (Rosen, 2000, p. 602). A second meta-analysis (Marshall \& Biddle, 2001) applied to exercise presented empirical data on the constructs of the TTM. Their findings did not confirm the presence of the hierarchical order structure of the POC. In addition, the authors found similar patterns of change for individual process use across stage transitions, which indicate that stage-by-process interactions are not evident for the domain of physical activity (see also Lippke \& Plotnikoff, 2009).

If the hierarchical structure of five experiential and five behavioural processes are not relevant in the exercise domain and if people use POC of both hierarchical factors similarly in post-action stages interventions for CAD-patients focusing on behavioural processes only will not be most effective. For maintaining exercise, experiential processes seem also to be relevant.

Originally, POC were derived from several systems of psychotherapy to treat addictions. The relevance and importance of these behaviour change processes may change in the physical activity domain. Changing health-related behaviours is either related to stopping negative behaviours (e.g., smoking) or to initiating positive behaviours (e.g., physical activity).

The TTM was designed for smoking cessation. In this case, the goal of the behaviour change process is to quit smoking. Whereas, when a person makes the decision to 
become physically active on a regular basis, the aim of the behaviour change process is to begin and maintain a healthy behaviour. It might be possible that a person needs to make different efforts when beginning and maintaining a healthy behaviour than when omitting an unhealthy behaviour. The person will have to efficiently integrate exercise into his or her everyday life and he or she will have to reinitiate the exercise behaviour continuously.

Most of the studies addressing exercise behaviour and using the TTM are crosssectional (Sutton, 2005). Cross-sectional studies are unable to clarify whether the postulated determinants of the TTM are predictive of changes in exercising or whether these determinants are a reflection of increased experience with exercise. Such a design fails the demand of causal analysis (Singer \& Willett, 2003). To understand, the process of behaviour change longitudinal studies are needed. Nigg (2001) examined the predictive power of the POC in relation to exercise behaviour. The results of the panel analysis showed that the POC did not significantly lead to exercise. The authors suggest that the time lag of 3 years between baseline and follow-up explained the non-significance.

Time lags of 6 month were used in a longitudinal study of Plotnikoff, Hotz, Birkett, and Courneya (2001). Healthy adults were asked at baseline, 6 months and 12 months later about POC and SOC. The results of the 10 POC across each respective stage generally reflect the hierarchical order structure. Persons who were in the post-action stages (action or maintenance) use two experiential processes (environmental re-evaluation and consciousness raising) and four behavioural processes (counterconditioning, reinforcement management, self-liberation, and stimulus control).

This paper wants to further understand the theoretical framework of the POC in order to enable the creation of effective interventions for CAD patients who need to successfully integrate their learned exercise behaviour into their daily routines after discharge. According to the TTM framework, CAD patients are in the post-action stages after discharge. The first purpose of this study is to analyse whether the POC include two separate, latent variables of five experiential processes and five behavioural processes. According to recent results, it is hypothesized that this theoretical division is not apparent in exercise application of the model.

The second aim of this paper is analysing whether POC lead to follow-up exercise or vice versa, and which POC do so in particular. We postulate that POC support the exercise behaviour change process. In addition, CAD patients in the post-action stages are using the same POC as healthy people. According to the results of Plotnikoff et al. (2001), these are environmental re-evaluation and consciousness raising as well as counter-conditioning, reinforcement management, self-liberation, and stimulus control.

\section{Method}

\section{Procedure}

The baseline data of $204 \mathrm{CAD}$ patients were collected consecutively after discharge from December 2003 to October 2004 in five German rehabilitation centres. A physician judged whether suitable CAD patients were able to join in the study. Inclusion criteria for patients were: (1) diagnosis of CAD, (2) low to moderate cardiac risk, so they were able to exercise with at least $1 \mathrm{~W} / \mathrm{kg}$ weight, and (3) no physical disorders that might hinder moderate exercise (e.g., arthrosis). Participants were excluded, if they exceeded a critical value of anxiety or depression and if their answers were biased by social desirability. Evaluations were conducted with questionnaires (see section measures). 
Participation was voluntary. After the CAD patients had given their written consent, they received a questionnaire 1-3 weeks after discharge (baseline) and again 6 month after discharge (follow-up).

\section{Participants}

Out of 204 questionnaires 147 (72\%) could be analysed. Reasons for missings were (1) CAD patients did not sent the first questionnaire back (16\%) or (2) they were excluded because they had more than $30 \%$ of missing values (1\%), (3) they had a high pathology value of anxiety (2\%) or (4) they showed high social desirability (9\%).

The majority of the sample was male (91\%), married (81\%), and employed (61\%). On average, the participants were 55 years old ( $S D \quad 10)$. In that respect, the sample is representative of CAD patients in general (Grande \& Badura, 2007).

Of the participants, 108 provided data at baseline and follow-up. Concerning demographic details and study variables (POC and exercise) completers did not differ significantly from non-completers ( $N$ 39). However, completers were more often non-smokers compared to non-completers $(p \quad .01)$, which lead to a bias of overrepresentation of people living a healthy life-style.

\section{Measures}

Processes of change questionnaire

Nigg, Norman, Rossi, and Bensovich (1999) developed a questionnaire with 30 physical activity scenarios (three items for each process) to analyse the 10 POC (cf. Table 1). Individuals were asked to recall the past month and to estimate on a five-point Likert scale (ranging from 1 for never and 5 for repeatedly) how relevant the scenario is or has recently been. A working group under H. D. Basler and S. Keller (Phillipps-University of Marburg, University of Hawaii at Manoa) translated this version into German (Maier \& Basler, 2003). Internal consistency of experiential and behavioural processes had a mean of .83 and .87 , respectively. This version was already used in a German sample with CAD risk factors (Schmid, Keller, Jäkle, Baum, \& Basler, 1999).

\section{Stages of change questionnaire}

Considering recommendations for staging measures (Reed, Velicer, Prochaska, Rossi, \& Marcus, 1997), we used a staging algorithm that allows subjects to categorize themselves into one of five SOC. The instrument includes a clear definition of regular exercise, its frequency and duration. For the CAD patients of this study, we used the definition of exercise according to the American Association of Cardiovascular and Pulmonary Rehabilitation. The algorithm has been used in most published studies on exercise SOC (e.g., for CAD patients, Bock et al., 1997; Jue \& Cunningham, 1998) and was translated into German (Basler, Jäkle, Keller, \& Baum, 1999).

\section{Activity questionnaire}

The Freiburger Fragebogen was developed to analyse activities with moderate intensity in epidemiological studies (Frey, Berg, Gratwohl, \& Keul, 1999). The instrument assesses three indices of activity: (1) activities during the day, like climbing stairs or running one's errands, (2) irregularly activities during leisure time, like taking a walk or a bike ride, (3) regular sport activities, like swimming or - especially for CAD 
patients - attending an out-patient cardiac exercise group. The indices are a calculation of the energy expenditure of the different activities and are based on the ratio of work metabolic rate to resting metabolic rate (MET). The compendium of Ainsworth and colleagues was used for classification (Ainsworth et al., 2000). Retests of the second and third indices indicated high stability over 2 weeks $\left(\begin{array}{lll}r & .5-.9\end{array}\right)$ and 6 months $\left(\begin{array}{ll}r & .4-.6\end{array}\right)$. Additionally, these indices show good values for validity (Frey et al., 1999). The questionnaire had already been used in a sample of German CAD patients (Frey, Berg, Halle, Hounker, \& Keul, 1995). This study refers only to activities during leisure time and regular sport activities. Due to poor validity in this study, activities during the day were excluded from the study.

\section{Exclusion criteria}

The Hospital Anxiety and Depression Scale - German was used to estimate the parameter value of anxiety and depression (Herrmann, Buss, \& Snaith, 1995). CADpatients often suffer from anxiety and depression and if these psychological strains become serious patients will be hindered from being physically active (Beck, Rush, Shaw, \& Hautzinger, 1999). Participants with a cutoff value of 14 on a scale from 0 (without pathological findings) to 21 (with pathological findings) were seriously anxious and depressed and were excluded.

Social desirability is often a problem in studies that are based on self-reports and can be estimated by 11 questions concerning moral behaviour (e.g., 'I do not say the truth, always'; 'Sometimes I get angry'; 'If I can enter a movie-theater without paying and nobody will see me I would probably do it'; Dahlstrom, Welsh, \& Dahlstrom, 1972). Individuals who answered 'yes' less than 9 times to the 11 social desirability items described below were deemed to be answering with a high degree of social desirability and were excluded from analyses.

\section{Statistical analyses}

We used structural equation modelling (SEM) with nested model comparison and first tested the hierarchical structure of the POC. Secondly, SEM was used in terms of crosslagged panel design to examine the hypotheses of whether POC precede behaviour or vice versa and whether specific POC are more effective in supporting CAD patients in maintaining exercise after discharge.

Analyses for the first hypothesis

Three structural models were compared to test the hierarchical structure.

Ten factors model. In this model, the associations among the POC are expressed as 10 factors representing the POC as independent dimensions of change. This model suggests that subjects differentiate among the POC in their attempts to maintain exercise after discharge.

One bierarchical-factor model. In this model, the associations among the 10 POC are expressed as a single, general POC factor. Support for this model would suggest that subjects do not differentiate among the POC. 
Two bierarchical-factors model. In this model, the associations among the 10 POC are expressed as two hierarchical factors, representing experiential and behavioural processes. The two-factor model tested the possibility that subjects differentiated among the POC at the level of the hierarchical order structure.

\section{Analyses for the second hypothesis}

Ten models in terms of cross-lagged panel design were conducted (one model for each process of the POC). Each model examines the correlation between Variable A (one POC at Time 1) and Variable B (exercise at Time 2) as compared to the correlation between Variable B (exercise at Time 1) and Variable A (one POC at Time 2). Cross-lags between POC and exercise were of primary interest. Furthermore, the models include longitudinal correlations within construct paths allowing controlling for covariance stability and cross-sectional correlations between POC and exercise. Because baseline and follow-up measures were the same, covariances between item errors of the same measure (e.g., Item 1 at baseline and Item 1 at follow-up) were permitted.

The global fit of the comparative model and the cross-lagged panel models was assessed with three different fit indices (Hu \& Bentler, 1999). Absolute fit measures estimate the discrepancy between the empirical sample covariance matrix and the implied covariance matrix of the postulated model: a cutoff value smaller than .06 for root mean error of approximation (RMSEA) and a standardized root mean squared residual (SRMR) smaller than .08 argue for a good absolute model fit. Incremental fit measures compare the hypothetical model to an independence model assuming that all variables of the model are independent. A comparative fit index (CFI) of greater than .95 indicates good model fit (Kline, 1998). If sample size is low $(<250)$, Hu and Bentler (1999) recommend the combination of CFI with SRMR to evaluate model fit.

Multiple imputation has been carried out as missing value replacement method (Schafer \& Graham, 2002). All in all, a maximum of seven missing values per item had to be replaced. A systematic bias is not probable (Schafer, 1997).

Maximum-likelihood estimations were used for the comparative analyses. For the chi-squared difference test, alpha-level was set to $p<.05$. The models were calculated with the statistical program AMOS 7.0.

\section{Results}

The sample was classified into the two post-action SOC: at baseline, $62 \%$ of the sample was in action and $38 \%$ of the sample was in maintenance. At follow-up, $45 \%$ of the sample was in action and $55 \%$ of the sample was in maintenance, respectively. $42 \%$ of the participants attended an out-patient cardiac exercise group at follow-up.

The model fit of the two hierarchical-factors model is only partly convincing (SRMR .07; RMSEA .07; CFI .88) because it exceeds the critical value of SRMR $(<.06)$ and falls below the critical value of CFI $(>.95)$. The two hierarchical-factors model fits significantly better than the one hierarchical-factor model ( $\chi^{2}$ diff $19.04(1)$, $p<.001)$ and the ten factors model ( $\chi^{2}$ diff $\left.233.6(9), p<.001\right)$. Although the results confirm the theoretically postulated hierarchical order structure for the POC, the correlation between the experiential and the behavioural processes is very high ( $r \quad .98, p<.001$ ). Means, standard deviation, factor loadings, and communality of the two hierarchical-factors model are shown in Table 2. As can be seen in Table 2, 
Table 2. Scale means $(M)$, standard deviations $(S D)$, communality, and factor loadings of the two hierarchical factors model of the processes of change $(N=147)$

\begin{tabular}{lcccc}
\hline Processes of change & $M$ & $S D$ & Communality & Factor loading \\
\hline Experiential & & & & \\
CR & 2.98 & 0.88 & 0.55 & 0.74 \\
DR & 2.58 & 0.84 & 0.34 & 0.59 \\
ER & 3.24 & 0.53 & 0.79 & 0.89 \\
SR & 3.84 & 0.87 & 0.97 & 0.98 \\
SOL & 3.31 & 0.83 & 0.57 & 0.75 \\
Behavioural & & & & \\
CC & 2.92 & 0.89 & 0.65 & 0.81 \\
HR & 2.61 & 1.09 & 0.15 & 0.39 \\
RM & 3.59 & 0.95 & 0.92 & 0.96 \\
SEL & 3.53 & 0.92 & 0.98 & 0.89 \\
SC & 3.57 & 1.15 & 0.67 & \\
\hline
\end{tabular}

Note. CR, consciousness raising; DR, dramatic relief; ER, environmental re evaluation; SR, self re evaluation; SOL, social liberation; CC, counter conditioning; HR, helping relationships; $\mathrm{RM}$, reinforcement management; SEL, self liberation; SC, stimulus control (SC).

communality for helping relationships is very low, indicating low internal consistency for that scale.

Bivariate correlations among the variables of the 10 cross-lagged panel models are depicted in Table 3, indicating low to moderate associations.

Table 3. Correlations among the variables of the 10 cross lagged panel models (each model $N=108$ )

\begin{tabular}{lcccccccccccc}
\hline & ExI & Ex2 & CRI & DRI & ERI & SRI & SOLI & CCI & HRI & RMI & SELI & SCI \\
\hline Ex2 & & & .1 & .04 & .06 & .18 & .12 & .1 & .1 & .16 & $.21^{*}$ & $.33^{*}$ \\
ExI & & $.21^{*}$ & .17 & .17 & .13 & $.24^{*}$ & .12 & .12 & .14 & .19 & $.26^{*}$ & .18 \\
CR2 & .03 & $.19^{*}$ & $.55^{*}$ & & & & & & & & & \\
DR2 & .07 & .01 & & $.53^{*}$ & & & & & & & & \\
ER2 & .01 & $.2^{*}$ & & & $.32 *$ & & & & & & & \\
SR2 & .19 & $.19 *$ & & & & $.61^{*}$ & & & & & \\
SOL2 & .04 & .15 & & & & & $.48^{*}$ & & & & & \\
CC2 & .13 & $.31^{*}$ & & & & & & $.44^{*}$ & & & & \\
HR2 & .06 & .13 & & & & & & & $.57^{*}$ & & & \\
RM2 & .12 & $.26^{*}$ & & & & & & & & $.56 *$ & & \\
SEL2 & .1 & $.26^{*}$ & & & & & & & & & $.34 *$ & \\
SC2 & $.24^{*}$ & $.29 *$ & & & & & & & & & & $.66^{*}$ \\
\hline
\end{tabular}

Note. CR, consciousness raising; DR, dramatic relief; ER, environmental re evaluation; SR, self re evaluation; SOL, social liberation; CC, counter conditioning; HR, helping relationships; RM, reinforcement management; SEL, self liberation; SC, stimulus control (SC); I = baseline, $2=$ follow-up; $* p<.05$.

The global fit indices of the 10 cross-lagged panel models indicate each with good model fit with SRMR and RMSEA lower than .08 and .06, respectively, and CFI greater than .95 in any model. 


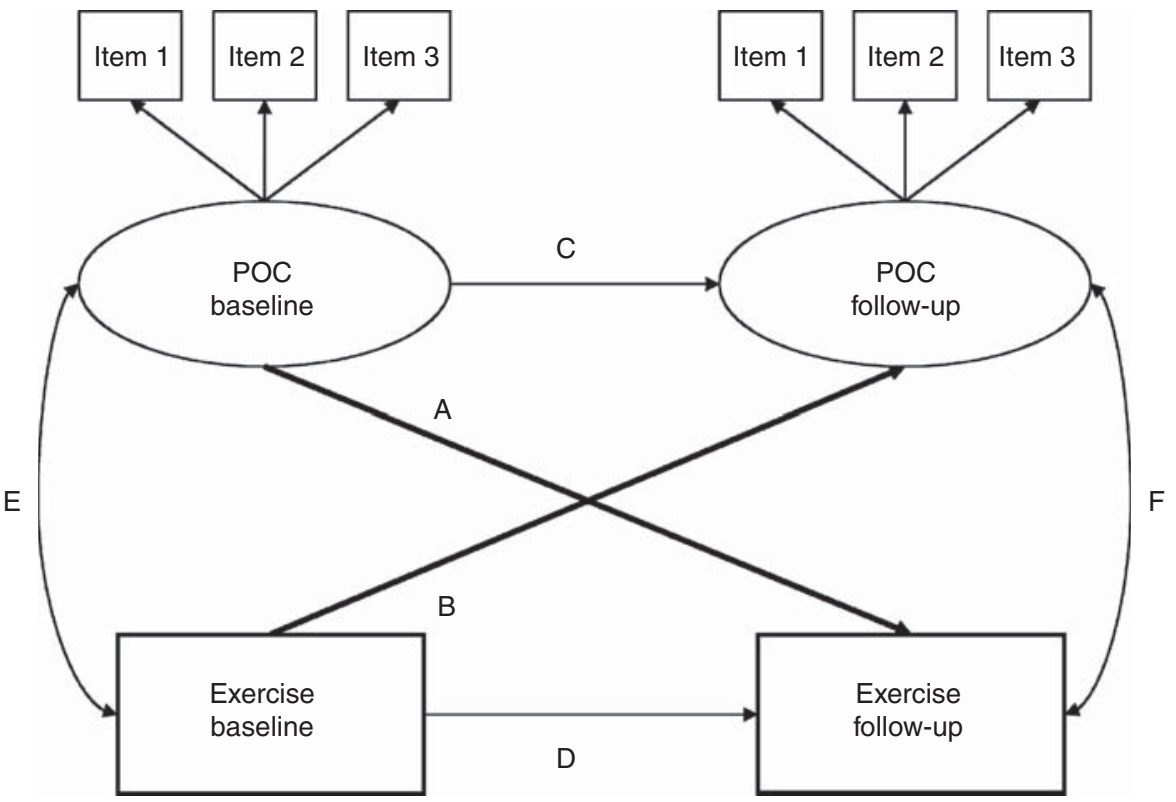

Figure I. Cross lagged panel model with indices: A, antecedence cross lag; B, consequence cross lag; C, autoregressive path for POC; D, autoregressive path for exercise; E, cross sectional path at baseline; $\mathrm{F}$, cross sectional path for follow up $(\mathrm{N}=108)$. Please insert values of Table 4 into this model. Note. The model does not include error terms. Circles represent latent variables that cannot be observed directly, while rectangles represent measured variables.

Cross-lagged panel analysis is pictured in Figure 1. Standardized effects of the 10 cross-lagged panel models are depicted in Table 4 (please compare the upper-case letters A-F in Table 4 and Figure 1).

Beta-weights of the autoregressive paths of the POC (baseline to follow-up of the same variable) are the strongest. They indicate a good stability of the POC. Beta-weights of the autoregressive paths of the POC are stronger than beta-weights of the autoregressive path of exercise indicating that exercise is less stable than psychological cognitions. The crosslags from consciousness raising, reinforcement management, self-liberation, and stimulus control to follow-up exercise (antecedence cross-lags) are significant and show stronger beta-weights than the cross-lags from exercise to those follow-up POC (consequence cross-lags). Consequence cross-lags are not significant in any case.

Chi-squared difference tests show, that for consciousness raising ( $\chi^{2}$ diff 6.2 , $p$.013), for reinforcement management $\left(\chi^{2}\right.$ diff $\left.7.6, p \quad .006\right)$, for self-liberation $\left(\chi^{2}\right.$ diff $\left.\quad 6.5, p \quad .01\right)$, and for stimulus control $\left(\chi^{2}\right.$ diff $\left.9.7, p \quad .002\right)$ antecedent cross-lags are statistically significant for the model-fit, respectively. If these antecedent cross-lags are eliminated the model-fit will be decreased. Hence, these particular POC are predictive of exercise behaviour at follow-up.

\section{Discussion}

For the first time, a longitudinal analysis of the processes of exercise behaviour change with CAD patients has been conducted. This paper wants to further understand the theoretical framework of the POC in the post-action stages. 


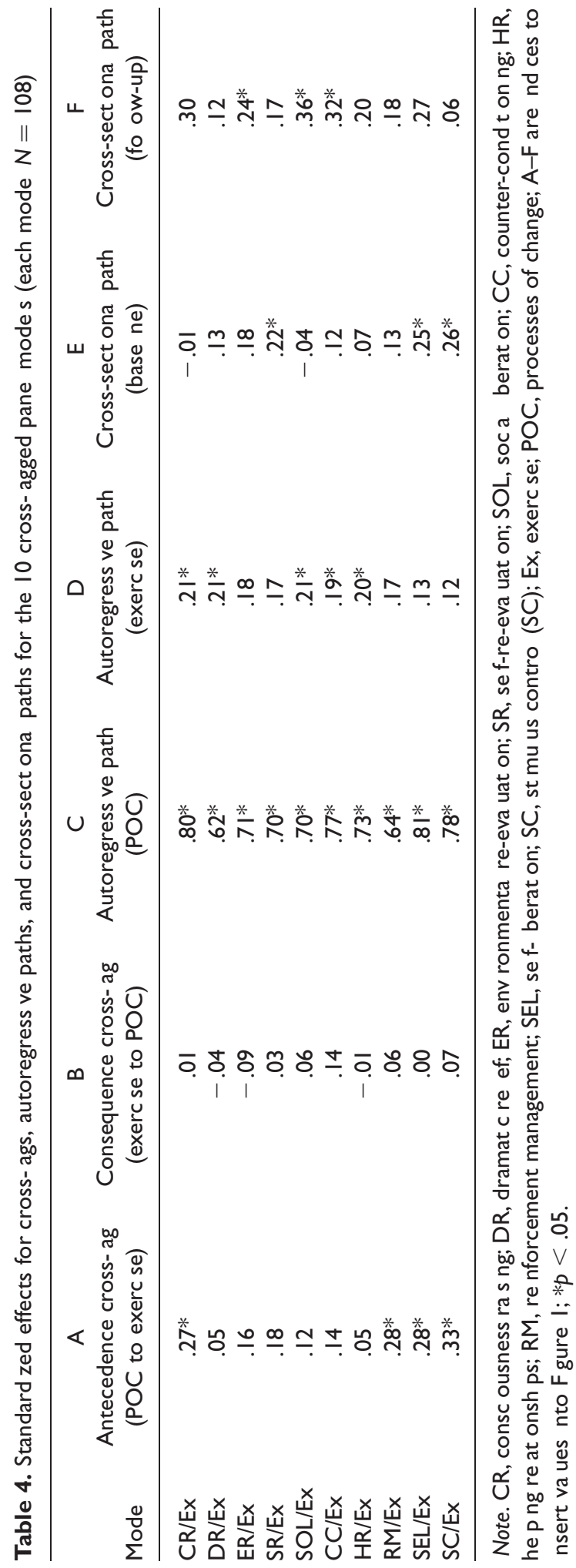


The first hypothesis has to be rejected. For CAD patients after discharge, the hierarchical order structure of the POC is statistically apparent in the post-action stages. Nevertheless, experiential processes and behavioural processes show a very high correlation. Marcus, Rossi, Selby, Niaura, and Abrams (1992) reported similar results in one of the first publications on POC and physical activity. Their findings indicated a correlation of $r \quad 908$ among experiential and behavioural processes. Thus, their argument 'that the improvement in fit of the two hierarchical-factors model over the one hierarchical-factor model is not substantively meaningful' must be reiterated. In contrast to the TTM framework, it seems to be that the distinction between experiential and behavioural processes may not be worth preserving in the physical activity domain. Further research is needed to examine the presence of the hierarchical order structure of the POC. Interventions focusing on behavioural processes only will not be most effective for CAD patients maintaining physical activity after discharge. Experiential processes should also be taken into account. In the presented study, consciousness raising was used in post-action stages. Offering information is an effective strategy to increase physical activity (Loughlan \& Mutrie, 1997). That seems to be relevant for healthy people and for CAD patients alike.

The second hypothesis has to be accepted. Due to the powerful antecedent cross-lags, it is more likely that POC leads to exercise rather than exercise leads to follow-up POC.

Consistent with the POC framework and the results of Plotnikoff et al. (2001), CAD patients use behavioural processes to control their environment (e.g., anticipate barriers to increase the ability of planning for them), to reward themselves (e.g., doing or buying something special after reaching the self-determined goal) or they make a firm commitment. In addition, CAD patients also use experiential processes while seeking information about exercise and its benefits. These four processes of behaviour change (stimulus control, reinforcement management, self-liberation, and consciousness raising) are the only ones which are predictive and which support CAD patients in successfully transferring exercise behaviour learned during rehabilitation into their everyday life.

Lowther, Mutrie, and Scott (2007) analysed key-processes for actors progressing to maintenance in a longitudinal study with 370 healthy adults. Relevant processes of exercise behaviour change were social liberation, counter-conditioning, helping relationships, and self-liberation. Self-liberation is here the most important process for maintaining physical activity.

According to the result of the presented study, it also seems relevant that CAD patients make an individual commitment to keep exercising. An intervention should therefore focus on self-liberation by allocating an agreement on how to exercise in the next weeks, for instance.

Beyond that, CAD-patients can define a detailed plan for how to enact their intention (e.g., If situation X is encountered, then I will be physically active; Gollwitzer, 1999). Such if-then plans or implementation intentions spell out the when, where, and how of goal striving in advance and they delegate the control of a person's behaviour to situational cues. A meta-analysis of 94 independent tests shows (Gollwitzer \& Sheeran, 2006) that implementation intentions have positive effects of medium to large magnitude on goal attainment.

Sniehotta et al. (2005) examine an intervention for CAD-patients addressing planning processes (inter alia implementation intentions) and self-regulatory processes. The results provide evidence that both strategies enhance physical activity 4 month after 
discharge, whereas self-regulatory strategies were the strongest predictor for exercise. Self-regulation refers to any efforts undertaken in order to alter one's behaviour. Kanfer and Hagermann (1987) describe self-regulation with three steps: first, a person focuses on his or her behaviour concerning the desired goal (self-monitoring). Then, the person compares his or her actual behaviour to the desired behaviour (self-evaluation). If there is a gap between the 'ought' and the 'actual' state, the person reacts with a reward or with a penalty (self-reinforcement). The POC framework does not explicitly address the concept of self-regulation. The TTM includes stimulus control and reinforcement management, which come close to the idea of self-regulation and which were used by CAD patients remaining physically active.

Nevertheless, planning processes and self-regulation processes seem to be important strategies for behaviour maintaining in post-intentional individuals. The TTM does not refer to these relevant strategies in detail. So it may be that individuals use techniques and strategies that are not measured by current instruments of the TTM.

Bearing DiClemente's statement in mind that the TTM is not a religion, but rather a heuristic model for exploring the behaviour change process (DiClemente, 2005, p. 1048), it might be more effective to adapt the model and to include additional processes like planning processes and self-regulatory processes. Further research is needed to analyse which strategies are important in the process of maintaining physical activity. Knowing these relevant strategies, practitioners are able to create effective interventions for supporting CAD patients in integrating exercise behaviour into their everyday life.

It is important to acknowledge the limitations of our study. First, the sample size of the first analysis in particular is very small. That might be the reason why the structural models of the first analysis are only partly convincing. Thus, the results of these competing models should be interpreted very carefully. In general, analysing a confirmatory factor analysis with a small sample size yields to a moderate to high sampling error, so that the solution of the competing models at baseline may be not very stable. Second, exercise has low and sometimes not significant standardized effects on the longitudinal correlations within construct paths. Low covariance stability could be suggestive of low validity of the activity questionnaire. In general, self-reports of physical activity with low to moderate intensity have problems in validity and reliability (Dishman, 2006). Future studies should measure physical activity objectively (e.g., accelerometer). Third, the small sample size and the intention to analyse each POC in detail made it necessary to run 10 models on the same data. It should, therefore, be considered that there is an increased probability of the results being significant due to stochastic reasons.

\section{References}

Ainsworth, B. E., Haskell, W. L., Whitt, M. C., Irwin, M. L., Swartz, A. M., Strath, S. J., et al. (2000). Compendium of physical activities: An update of activity codes and MET intensities. Medicine and Science in Sports and Exercise, 32(9), 498516.

Bandura, A. (1982). Self efficacy mechanism in human agency. American Psychologist, 37, 122147.

Basler, H. D., Jäkle, C., Keller, S., \& Baum, E. (1999). Selbstwirksamkeit, Entscheidungsbalance und die Motivation zu sportlicher Aktivität [Self efficacy, decisional balance, and the motivation to do vigorous exercise]. Zeitschrift für Differentielle und Diagnostische Psychologie, 20(3), 203216. 
Beck, A. T., Rush, A. J., Shaw, B. F., \& Hautzinger, M. (1999). Kognitive therapie bei depressionen (5 Aufl.). Weinheim: Beltz.

Bock, B. C., Albrecht, A. E., Traficante, R. M., Clark, M. M., Pinto, B. M., Tilkemeier, P., et al. (1997). Predictors of exercise adherence following participation in a cardiac rehabilitation program. International Journal of Behavioral Medicine, 4, 6075.

Dahlstrom, W. G., Welsh, G. S., \& Dahlstrom, L. E. (1972). An MMPI handbook clinical interpretation. Minneapoli, MN: University of Minnesota Press.

DiClemente, C. C. (2005). A premature obituary for the transtheoretical model: A response to West. Addiction, 100, 10461048.

Dishman, R. K. (2006). Measurement of physical activity. In L. W. Poon, W. Chodzko Zajko, \& P. D. Tomporowski (Eds.), Active living, cognitive functioning and aging (pp.91 112). Champaign, IL: Human Kinetics.

Frey, I., Berg, A., Gratwohl, D., \& Keul, J. (1999). Freiburger questionnaire on physical activity design, validation and application [German]. Social and Preventive Medicine, 44, 5564.

Frey, I., Berg, A., Halle, M., Huonker, M., \& Keul, J. (1995). Quantifizierung und Beurteilung der Freizeitaktivitäten von Herzgruppenteilnehmern [German]. Herz/Kreislauf, 27, 387391.

Gollwitzer, P. M. (1999). Implementation intentions: String effects of simple plans. American Psychologist, 54, 493503.

Gollwitzer, P. M., \& Sheeran, P. (2006). Implementation intentions and goal achievement: A meta analysis of effects and processes. In M. P. Zanna (Ed.), Advances in experimental social psychology (Vol. 38, pp. 69 119). San Diego, CA: Elsevier.

Grande, G., \& Badura, B. (2007). Cardiac rehabilitation from a health systems analysis perspective. In J. Jordan, B. Bardé, \& A. M. Zeiher (Eds.), Contributions toward evidence based psychocardiology: A systematic review of the literature (pp. 107 123). Washington, DC: American Psychological Association.

Herrmann, Ch., Buss, U., \& Snaith, R. P. (1995). HADS D Hospital Anxiety And Depression Scale Deutsche version [German]. Göttingen: Hans Huber.

Hu, L., \& Bentler, P. M. (1999). Cutoff criteria for fit indexes in covariance structure analysis: Conventional criteria versus new alternatives. Structural Equation modeling, 6(1), 155.

Jue, N. H., \& Cunningham, S. L. (1998). Stage of exercise behavior change at two time periods following coronary artery bypass graft surgery. Progress in Cardiovaskular Nursing, 13(1), 2333.

Kanfer, F. H., \& Hagermann, S. (1987). A model of self regulation. In F. Halisch \& J. Kuhl (Eds.), Motivation, intention, and volition (pp. 193 307). Berlin: Springer.

Kline, R. B. (1998). Principles and practice of structural equation modeling. New York: Guilford Publications.

Kolenda, K. D. (2005). Sekundärprävention der koronaren Herzkrankheit: Effizienz nachweisbar [Secondary prevention of coronary artery disease: Effectiveness demonstrated]. Deutsches Aerzteblatt, 102A, 18891895.

Leon, A. S., Franklin, B. A., Cosat, F., Balady, G. J., Berra, K. A., Stewart, K. J., et al. (2005). Cardiac rehabilitation and secondary prevention of coronary heart disease AHA Scientific Statement. Circulation, 111, 369376.

Lippke, S., \& Plotnikoff, R. W. (2009). The protection motivation theory within the stages of the transtheoretical model stage specific interplay of variables and prediction of exercise stage transitions. British Journal of Health Psychology, 14(2), 211 229. doi:10.1348/ $135910708 \times 399906$

Loughlan, C., \& Mutrie, N. (1997). An evaluation of the effectiveness of three interventions in promoting physical activity in a sedentary population. Health Education Journal, 56, 154165.

Lowther, M., Mutrie, N., \& Scott, E. M. (2007). Identifying key processes of exercise behavior change associated with movement through the stages of exercise behavior change. Journal of Health Psychology, 12(2), 261272. 
Maier, A., \& Basler, H. D. (2003). Gibt es eine Stufenspezifität bei Änderungsstrategien bei sportlicher Aktivität [German]. Zeitschrift für Gesundheitspsychologie, 11(4), 125131.

Marcus, B. H., Rossi, J. S., Selby, V. C., Niaura, R. S., \& Abrams, D. B. (1992). The stages and processes of exercise adoption and maintenance in a worksite sample. Health Psychology, 11, 386395.

Marcus, B. H., \& Simkin, L. R. (1994). The transtheoretical model: Applications to exercise behavior. Medicine and Science in Sports and Exercise, 26, 14001404.

Marshall, S. J., \& Biddle, J. H. (2001). The transtheoretical model of behavior change: A meta analysis of application to physical activity and exercise. Annals of Behavioral Medicine, 23, 229246.

Müller Fahrnow, W., Karoff, M., \& Nowossadeck, E. (2003). CARO II: Studie zu Qualitätsmanage ment und Nachhaltigkeit [Caro II: Study on quality management and sustainability]. Herzmedizin. Zeitschrift für Kardiologie, Rebabilitation und Prophylaxe, 2, 107.

Niebauer, J., Hambrecht, R., Velich, T., Hauer, K., Marburger, Ch., Kälberer, B., et al. (1997). Attenuated progression of coronary artery disease after 6 years of multifactoral risk intervention. Circulation, 96, 25342541.

Nigg, C. R. (2001). Explaining adolescent exercise behavior change: A longitudinal application of the transtheoretical model. Annals of Behavioral Medicine, 23, 1120.

Nigg C. R., Norman, G. J., Rossi, J. S., \& Bensovich, S. V. (1999). Processes of exercise behavior change: Redeveloping the scale. Poster presented at SBM, San Diego, CA.

Plotnikoff, R. C., Hotz, S. B., Birkett, N. J., \& Courneya, K. S. (2001). Exercise and the transtheoretical model: A longitudinal test of a population sample. Preventive Medicine, 33, 441452.

Prochaska, J. O., \& DiClemente, C. C. (1986). Toward a comprehensive model of change. In W. R. Miller \& N. Heather (Eds.), Treating addictive behaviors: Processes of change (pp. 3 27). New York: Plenum.

Prochaska, J. O., Reeding, C. A., \& Evers, K. E. (2002). The transtheoretical model and stages of change. In K. Glanz, B. K. Rimer, \& F. M. Lewis (Eds.), Health behaviour and health education: Theory, research and practice (3rd ed., pp. 99 120). San Francisco, CA: Jossey Bass.

Reed, G. R., Velicer, W. F., Prochaska, J. O., Ross, J. S., \& Marcus, B. H. (1997). What makes a good stage algorithm: Examples from regular exercise. Science of Health Promotion, 12(1), 5766.

Rosen, C. S. (2000). Is the sequencing of change processes by stage consistent across health problems? A meta analysis. Health Psychology, 19, 593604.

Schafer, J. L. (1997). Analysis of incomplete multivariate data. New York: Chapman and Hall.

Schafer, J. L., \& Graham, J. W. (2002). Missing data: Our view of the state of the art. Psychological Methods, 7, 147177.

Schlicht, W., Kanning, M., \& Bös, K. (2006). Psychosocial interventions to influence physical inactivity as a risk factor: Theoretical models and practical evidence. In J. Jordan, B. Bardé, \& A. M. Zeiher (Eds.), Contributions toward evidence based psychocardiology: A systematic review of the literature (pp. 107 123). Washington, DC: American psychological association.

Schmid, S., Keller, S., Jäkle, C., Baum, E., \& Basler, H. D. (1999). Kognition und Motivation zu sportlicher Aktivität eine Längsschnittstudie zum Transtheoretischen Modell [Cognition and motivation for sporting activities a longitudinal study on the Transtheoretical Model]. Zeitschrift für Gesundheitspsychologie, 7(1), 2126.

Singer, J. D., \& Willett, J. B. (2003). Applied longitudinal data analysis. New York: Oxford University Press.

Sniehotta, F. F., Schloz, U., Schwarzer, R., Fuhrmann, B., Kiwus, U., Behr, H., et al. (2005). Long term effects of two psychological interventions on physical exercise and self regulation after coronary rehabilitation. International Journal of Behavioral Medicine, 12, 244255. 
Sutton, S. (2005). Stages theories of health behavior. In M. Conner \& P. Norman (Eds.), Predicting bealth behavior (2nd ed., pp. 223 275). New York: Open University Press.

Thompson, P. D., Buchner, D., Pina, I. L., Balady, G. J., Williams, M. A., Marcus, B. H., et al. (2003). Exercise and physical activity in the prevention and treatment of arteriosclerotic cardiovascular disease. A statement from the council on clinical cardiology and the council on nutrition, physical activity and metabolism. Circulation, 107, 31093116.

Wannamethee, S. G., Shaper, G., \& Walker, M. (2000). Physical activity and mortality in older men with diagnosed heart disease. Circulation, 102, 13581363

West, R. (2005). Time for change: Putting the transtheoretical (stage of change) model to rest. Addiction, 100, 10361039.

World Health Organisation (2004). Atlas of heart disease and stroke. Retrieved from http://www. who.int/cardiovascular diseases/resources/atlas/en/ 